\section{Why rule encoding by animals in serial learning remains to be established}

\author{
E. J. CAPALDI, DONNA R. VERRY, \\ and T. L. DAVIDSON \\ Purdue University, West Lafayette, Indiana 47907
}

Serial-learning findings in our laboratory (Capaldi, Blitzer, \& Molina, 1979; Capaldi \& Molina, 1979; Capaldi, Verry, \& Davidson, 1980) indicate that rats anticipate elements of an orderly series of reward magnitudes by employing memories of earlier reward events in the series. Our findings are strongly inconsistent with deductions available from a rule-encoding explanation of serial learning (e.g., Hulse, 1978; Hulse \& Dorsky, 1977, 1979). The memory variables that influenced serial learning in our laboratory were extensively confounded in serial-learning investigations from Hulse's laboratory. Hulse (1980), in his critique of our work, does not directly address these points, arguing, instead, that due to allegedly important procedural differences between his seriallearning investigations and our own, our research fails to address the issue of rule learning.

Capaldi et al. (1980) were not unmindful of procedural differences between our laboratory and Hulse's. However, after examining these, Capaldi et al. suggested that experimental conditions employed in the two laboratories failed to differ meaningfully, a conclusion vigorously disputed by Hulse (1980). However, Hulse, in attempting to support his contention, has in two instances displayed a misunderstanding of our experimental procedures and his own, seeing differences when demonstrably none exist. The remaining variables emphasized by Hulse are mainly temporal in character. His treatment of temporal matters, we will show, lacks plausibility.

Contrary to Hulse (1980), we did not present the two exemplars of the decreasing rule, 4-0 and 16-4, in different orders each day. In another of our experiments (Capaldi et al., 1980, Experiment 2), sequences were presented in different orders over days. However, what difference this makes is obscure, since sequences were presented in different orders over days by Hulse and Dorsky (1979) in their Experiment 1 , as their procedure section (see p. 213) makes clear. In that experiment, Hulse and Dorsky employed a number of different sequences such as $10-5,5-3$, and so on, and these were presented "haphazardly" (their word) each day, so the sequences must have been presented in different orders over

Preparation of this report was supported by NSF Grant BNS 80-01171 to E. J. Capaldi. days. Hulse's experiments and our own do not differ in this particular.

It is true that Hulse and his associates used more sequence repetitions or training than we did, but Hulse (1980) is incorrect in suggesting that this constitutes an important difference between our respective investigations. This is because differences between the groups in Hulse's investigations usually appeared early and stabilized. Thus, extended training was as superfluous in his studies as it would have been in ours. As a typical example, differences between the monotonic and nonmonotonic groups employed by Hulse and Dorsky (1977) in their Experiment 1 appeared on Day 1 of training (see p. 494), maintaining themselves over the next 16 days of training, much or all of which was thus superfluous. Similar situations prevailed in Experiment 2 of Hulse and Dorsky (1977, see p. 497; 1978, see p. 217).

One temporal interval of importance to rule learning, according to Hulse, is that which separates elements of a sequence; another is that which separates sequences. All groups employed by Capaldi et al. (1980) received an interelement interval of about $15 \mathrm{sec}$, the same as that employed by Hulse and Dorsky $(1977,1979)$. The issue, then, is the intersequence interval. This interval was $10-15 \mathrm{~min}$ in Hulse and Dorsky (1977) and 10-20 min in Hulse and Dorsky (1979). In Capaldi et al. (1980), it was 15-20 min in Experiment 2, $30 \mathrm{~min}$ in Experiment 3, and either $30 \mathrm{~min}$ or $24 \mathrm{~h}$ in Experiment 1 -values, in most cases, quite similar to those employed in Hulse's laboratory. However, Hulse (1980), despite having employed an intersequence interval of as long as $20 \mathrm{~min}$ in his laboratory, suggests that the $30-\mathrm{min}$ intersequence interval employed in ours was too long to promote optimal rule encoding. How Hulse comes by this remarkable information-that an intersequence interval of $20 \mathrm{~min}$ is optimal for rule encoding, while a 30-min intersequence interval is not-is completely obscure, since he cites no evidence for it, none being available to our knowledge. However, Hulse's (1980) basis for identifying the optimal interelement interval is specified - that matter, according to him, being clear on a priori grounds. Yet, research from our laboratory indicates that temporal manipulations of the sort under discussion have little effect on the sort of memory variables shown to influence serial learning in Capaldi et al. (1980) and confounded in investigations from Hulse's laboratory (see, e.g., Capaldi \& Capaldi, 1970; Capaldi \& Morris, 1976; Capaldi \& Stanley, 1963). In the face of such contrary experimental evidence, however, Hulse (1980) has decided on a priori grounds that the interelement interval of 4 min used by Capaldi \& Molina (1979) is not optimal for rule encoding, and thus their findings with four- 
element patterns do not disconfirm his hypothesis. Hulse's temporal speculations are implausible not merely because they rest on no evidence whatever, but also because they are inconsistent with such evidence as is available. Let us look at the question of experimental variables from another point of view.

Hulse (1980) criticizes our work as "a misdirected effort to achieve parsimony." But, consider that Hulse begins his critique by admitting, admirably, that the literature fails to provide generally accepted definitions of rules or rule learning. He might have added that the literature also contains no formal specification of the experimental conditions conducive to rule learning in animals, much less any hint that such learning would fail to be optimal under many experimental conditions. While we regard Hulse's treatment of variables as arbitrary and implausible in many instances, had he even hinted at the importance he attaches to the precise values of certain variables used in his laboratory, we would have employed none other than those values in all cases.

We certainly regard Hulse's emphasis on rule learning and his view that animal serial learning can benefit by attending to human serial learning (and, we would add, vice versa) as positive developments, and we welcome them. However, we are convinced that Hulse has not made the case for rule learning in animals as yet, assuming it can be made. Our work makes quite clear that at least some serial learning in rats is accomplished without the agency of rule learning. This is a proposition that is now readily conceded by Hulse (1980), but which seems quite at variance with his prior publications on the topic.

\section{REFERENCES}

Capaldi, E. J., Blitzer, R. A., \& Molina, P. Serial anticipation pattern learning in two-element and three-element series. Bulletin of the Psychonomic Society, 1979, 14, 22-24.

Capaldi, E. J., \& Capaldi, E. D. Magnitude of partial reward, irregular schedules and a 24-hour ITI: A test of several hypotheses. Journal of Comparative and Physiological Psychology, 1970, 72, 203-209.

Capaldi, E. J., \& Molina, P. Element discriminability as a determinant of serial-pattern learning. Animal Learning \& Behavior, 1979, 7, 318-322.

Capaldi, E. J., \& Morris, M. D. The role of stimulus compounds in eliciting responses: Relatively spaced extinction following massed acquisition. Animal Learning \& Behavior, 1976, 4, 113-117.

Capaldi, E. J., \& Stanley, L. R. Temporal properties of reinforcement aftereffects. Journal of Experimental Psychology, $1963,65,169-175$.

Capaldi, E. J., Verry, D. R., \& Davidson, T. L. Memory, serial anticipation pattern learning, and transfer in rats. Animal Learning \& Behavior, 1980, 8, 575-585.

Hulse, S. H. Cognitive structures and serial pattern learning by rats. In S. H. Hulse, H. Fowler, \& W. K. Honig (Eds.), Cognitive processes in animal behavior. Hillsdale, N.J: Erlbaum, 1978.

Hulse, S. H. The case of the missing rule: Memory for reward vs. formal structure in serial-pattern learning by rats. Animal Learning \& Behavior, 1980, 8, 689-690.

Hulse, S. H., \& Dorsky, N. P. Structural complexity as a determinant of serial pattern learning. Learning and Motivation, $1977,8,488-506$.

Hulse, S. H., \& Donsky, N. P. Serial pattern learning by rats: Transfer of a formally defined stimulus relationship and the significance of nonreinforcement. Animal Learning \& Behavior, $1979,7,211-220$.

(Received for publication June 30, 1980; accepted June 30, 1980.) 